\title{
Fair Wages and Human Capital Accumulation In a Global ECONOMY
}

\begin{abstract} and employment levels are derived.

JEL Classification: F11, F16

Key Words: Globalisation, Unemployment, Fair Wages, Skill Upgrading

Udo Kreickemeier

University of Nottingham

School of Economics

University Park

Nottingham NG7 2RD

United Kingdom

udo.kreickemeier@nottingham.ac.uk
\end{abstract}

This paper analyzes trade in an asymmetric $2 \times 2 \times 2$ world, where the two countries ("Europe" and "America") differ in their preferences towards wage inequality. Fair wage considerations compress wage differentials in both countries, leading to involuntary unemployment of unskilled workers in equilibrium. European workers are more averse to wage inequality, and Europe is characterised by lower wage differentials as well as higher unemployment. Allowing for endogenous skill formation in both countries, the effects of a globalisation shock modelled as the entry of newly industrializing countries into the trading world - on prices 


\section{Introduction}

Heckscher-Ohlin trade theory has played a prominent role in the recent debate on the impact of globalisation shocks on labour markets in industrialised countries. Arguably, this so-called "trade-and-wages" debate has sparked the theory's comeback as a standard framework of analysis in international trade. As Krugman (2000) succinctly puts it: “...the Stolper-Samuelson theorem $[. .$.$] has moved from midterm exams into the heart of real-world debates over economic$ policy." This is ironic given that the effect of globalisation on involuntary unemployment appears to be a major concern to policy makers and the general public, while one of the core assumptions of the Heckscher-Ohlin (HO) framework are fully flexible factor prices, implying factor market clearing at all times.

Only a small subset of the contributions to the trade-and-wages literature allows for involuntary unemployment, typically by adding a binding minimum wage for unskilled labour or a fixed relative wage to the HO framework. ${ }^{1}$ Using unskilled and skilled workers as the two factors of production, Krugman (1995) introduced the dichotomy between an "American" approach, in which wages are fully flexible, and a "European" approach, in which relative wages are exogenously fixed. In this framework, globalisation, modelled as an increase in labour intensive exports by the group of newly industrializing countries (NIEs), leads to a decrease in the relative wage of unskilled workers in the "American" model and an increase in the rate of unskilled unemployment in the "European" model. Krugman (1995) describes a scenario of two alternative worlds with two countries each: America and the group of NIEs in a flexprice world,

\footnotetext{
${ }^{1}$ In the $2 \times 2$ Heckscher-Ohlin model, fixing one factor price in units of the numeraire good has the same effect as fixing relative factor prices, as long as full specialisation is ruled out and technology is held constant.
} 
Europe and the group of NIEs in a fixprice world.

Davis (1998) uses the dichotomy introduced by Krugman (1995) and applies it in a threecountry model, consisting of America, Europe and the group of NIEs. America and Europe trade freely with each other, there are fully flexible factor prices in America and a binding minimum wage rate in Europe. By the logic of the factor price equalisation theorem, free trade between the two countries equalises factor prices between them, but only unskilled workers in Europe experience unemployment. In this sense, American unskilled workers benefit from the European minimum wage, an effect that obviously can only be accounted for if one assumes that America and Europe are part of the same trading world. Globalisation is modelled as an opening-up of the integrated two-country world to trade with a third country, namely the group of NIEs. The most important lesson from Davis' paper is that with free goods trade the labour market outcomes in each country are determined by labour market institutions in both. The typical explanations for country specific labour market outcomes of globalisation by labour economists, as surveyed in for example Acemoglu (2003), tend to ignore this general equilibrium link working through integrated goods markets.

The present paper builds upon the three-country setup of Davis (1998) and extends it in two important respects. First, the HO production model with exogenous factor supplies is modified to allow for endogenous formation of human capital, following the classic paper by Findlay and Kierzkowski (1983). Second, involuntary unemployment is due to fair wage considerations on behalf of the workers, as modelled by Akerlof and Yellen (1990), rather than by an exogenous minimum wage. I will now discuss both extensions and their implications, starting with the way involuntary unemployment is introduced into the model. 
There is now plenty of evidence in support of the notion that involuntary unemployment can be explained at least in part by the fact that firms voluntarily pay non-market clearing wages in order to keep workers' morale high. Much of the evidence in support of this stems from surveys where business managers were asked about their firms' compensation policy, and the results suggest that the morale argument is relevant in both America and Europe: Agell and Lundborg (1995a, 2003) report results of two surveys for Sweden, whereas Bewley (1999) gives supportive results for the United States. This firm behavior is compatible with profit maximisation if one allows for work morale to have an influence on workers' effort, and hence on labour productivity. In a recent study, Fehr and Falk (1999) examined the same question in the laboratory, with striking results: In experiments where effort was a choice variable of the workers and not contractible, firms' wage offers were higher on average than workers' wage offers, and in most cases where underbidding by workers occurred, firms refused to accept the lower offers.

A theoretical framework compatible with these results is the fair wage model of Akerlof and Yellen (1990). ${ }^{2}$ Here, we develop a two-country-two-sector variant of this and use it as a framework for the analysis. Given the empirical evidence just cited, I allow for the fair wage mechanism to be present in both America and Europe. But due to different preferences towards inequality in the two countries, to be spelt out below, America has a lower rate of unemployment in equilibrium than Europe. This appears to be a more appropriate description of the asymmetry between the two countries than the strict dichotomy used by Krugman (1995) and Davis (1998).

\footnotetext{
${ }^{2}$ They build on earlier contributions by Solow (1979) and Akerlof (1982) where work morale was stressed as a reason for paying non-market clearing wages.
} 
The general equilibrium link pointed out by Davis (1998) has a strong implication in any framework with a $\mathrm{HO}$ production structure: even in the presence of labour market asymmetries between Europe and America, global shocks - i.e. shocks that hit both countries equally cannot lead to divergent wage paths between them. This is true both for a globalisation shock as described above and for a global technology shock. In a HO framework with diversified production, divergent wage paths can only be generated by country-specific technology shocks. Clearly, this strong result no longer holds if we modify the HO model to allow for the productivity of factors to differ between countries, and for a global shock to affect the productivity of factors in a country specific way. It is a model of this type that is developed here.

A straightforward way to incorporate international productivity differences between factors in a HO framework is provided by Findlay and Kierzkowski (1983). There, the number of skilled and unskilled workers as well as the skill level of those who choose to become skilled is determined endogenously. ${ }^{3}$ With different incentives to acquire skill between countries, this model allows wage paths to diverge between countries. In the present paper, the incentive to become skilled differs between countries because unemployment rates for unskilled workers are different.

The rest of the paper is structured as follows. Section 2 gives a brief non-technical discussion of the mechanisms driving the analysis. Section 3 presents the basic fair wage model. Section 4 embeds the fair wage model into a general equilibrium framework of a closed economy. Section 5 derives the equilibrium for the asymmetric two-country trading world and describes the effect that the globalisation shock has on the two countries. Section 6 concludes.

\footnotetext{
${ }^{3}$ Below, for simplicity the skill level of skilled workers is sometimes referred to as their "quality".
} 


\section{Non-technical Discussion}

The main contribution of the paper is to analyze the effects of a globalisation shock on an asymmetric two-country world ("Europe and America") with national factor markets but goods markets which are already fully integrated before the globalisation shock occurs. This shock is modelled as the two-country world opening up to trade with a previously isolated third country ("China"). At the goods prices of the pre-shock equilibrium, the third country is a net supplier of unskilled labour intensive goods.

Production technology in the two integrated countries is identical to the standard HeckscherOhlin model, the factors being skilled and unskilled labour. Unskilled workers in both countries are assumed to provide less than the normal effort if they perceive their wages to be too low relative to their skilled colleagues' wages. In the model, there is one crucial difference between America and Europe: The preferences of workers in Europe are more egalitarian than those of their American colleagues in the sense that they dislike wage inequality to a greater extent. While skill premiums in both countries are smaller than in a perfectly competitive labour market, they are smaller in Europe than in America, and involuntary unemployment of unskilled workers in Europe is higher in equilibrium.

In both countries, all individuals are born with equal abilities, and they decide at birth whether to acquire skill or to remain unskilled. The composition of the labour force in each country is then determined by the condition that the present values of skilled and unskilled workers' expected net lifetime incomes be equal. This implies that net wages of skilled workers during their (shorter) working life exceed expected net wages of unskilled workers. In Europe, the prospect of being potentially unemployed when unskilled does ceteris paribus give workers an 
additional incentive to acquire skill, as compared to America, where the rate of unemployment is lower. With decreasing marginal returns to skill acquisition (think for example of overcrowding effects in Universities), this implies that the skilled workforce is on average less well trained in Europe than in America. Because of the Heckscher-Ohlin production technology being the same in both countries, free goods trade equalises factor prices for labour in efficiency units. However, skilled workers in America receive a higher wage than their European colleagues because they are higher quality on average.

The globalisation shock puts downward pressure on the price of unskilled labour intensive goods, and in the adjustment process has knock-on effects on wages for both skilled and unskilled workers in America and Europe, the composition of each country's work force, and the unemployment rates in both countries. ${ }^{4}$

\section{The Fair Wage Model}

Involuntary unemployment is explained by a variant of the fair wage model developed by Akerlof and Yellen (1990). The adaptations made serve the sole purpose of making their one-sector model work in a two-sector general equilibrium framework. At each point in time, the two factors unskilled labour $L$ and skilled labour $H$ are supplied inelastically. The wage for unskilled workers is denoted by $w_{L}$. The wage for skilled workers varies with their skill level, and for a worker with skill level $q$ it is given by $q w_{H}$, where $w_{H}$ is the wage for one efficiency unit of

\footnotetext{
${ }^{4}$ Davis and Reeve (2002) combine the minimum wage model of Davis (1998) with the Findlay and Kierzkowski (1983) model. In their paper, the globalisation shock leaves goods prices constant, and the American labour market is isolated from the globalisation shock, as in Davis (1998).
} 
skilled labour. Both types of workers are able to choose their effort at work, and they supply effort according to the effort functions

$$
\begin{aligned}
e_{L} & =\min \left(\frac{w_{L}}{w_{L}^{*}}, 1\right) \\
e_{H} & =\min \left(\frac{q w_{H}}{q w_{H}^{*}}, 1\right)
\end{aligned}
$$

where $w_{L}^{*}$ and $q w_{H}^{*}$ are the fair wages for $L$ and $H$, respectively. This means that workers provide the normal level of effort, which is normalised to one, if they are paid at least their fair wage. If they are paid less then their fair wage, they reduce effort proportionately.

For each of the two groups, the fair wage has two determinants: first the market wage of the respective other group, and second the remuneration they could expect outside their own firm, taking into account that they might be unemployed with a probability that is equal to the factor-specific rate of unemployment. ${ }^{5}$ Hence, we have

$$
\begin{gathered}
w_{L}^{*}=\beta q w_{H}+(1-\beta)\left(1-U_{L}\right) w_{L} \\
q w_{H}^{*}=\beta w_{L}+(1-\beta)\left(1-U_{H}\right) q w_{H}
\end{gathered}
$$

where $U_{L}$ and $U_{H}$ are the factor-specific rates of unemployment, and $\beta$ is the weight attached to the respective other factors remuneration in one factor's determination of its fair wage. Following Akerlof and Yellen (1990), we assume that firms choose to pay fair wages if doing so does not diminish their profits.

\footnotetext{
${ }^{5}$ Instead of the expected wage rate, Akerlof and Yellen (1990) use the (hypothetical) market clearing wage rate of the respective group as the second determinant of the fair wage. The two approaches yield similar results as in the presence of involuntary unemployment for the respective factor both its expected wage and its market clearing wage lie below the actual wage. The approach used here is more straightforward to apply in a multi-sector model though.
} 
It would be true in a full employment version of the present model that the wage for skilled workers exceeds that of unskilled workers, i.e. $q w_{H}>w_{L}$ in this case. ${ }^{6}$ Using this result, it is straightforward to see that the following must hold in the equilibrium of the fair wage model:

$$
\begin{aligned}
& U_{L}>U_{H}=0 \\
& q w_{H}>q w_{H}^{*}>w_{L}=w_{L}^{*} \\
& e_{L}=e_{H}=1
\end{aligned}
$$

i.e., there is a strictly positive rate of unemployment $U=U_{L}$ for unskilled workers but full employment for skilled workers, the fair wage is binding only for unskilled workers, and both types of workers provide the normal effort. ${ }^{7}$

Using (4) to (6), one can derive an equilibrium relationship between the wage differential and the rate of unemployment. Using $\omega \equiv w_{L} / w_{H}$ to denote the wage differential for efficiency units of both types of labour, we get

$$
\frac{\omega}{q}=\alpha(U, \beta)=\frac{\beta}{\beta+(1-\beta) U}
$$

Following Akerlof and Yellen (1990), (7) is called the fair wage constraint. For a given value of the preference parameter $\beta$, the fair wage constraint describes equilibrium combinations between the

\footnotetext{
${ }^{6}$ As set out in section 2 above, workers are assumed to have the choice between career paths and as a consequence the expected net wages of skilled workers are higher in equilibrium than the expected net wages of their unskilled colleagues. For skilled workers, net wages are lower than gross wages due to the cost of education, while net wages equal gross wages for unskilled workers. Hence, $q w_{H}>w_{L}$ holds under full employment.

${ }^{7}$ These results are the same as in the model of Akerlof and Yellen (1990), but for the fact that in their framework one has to assume (quite reasonably) that skilled labour is the higher paid whereas it is derived endogenously in the present paper.
} 
rate of unemployment of unskilled workers and the relative gross wages of skilled and unskilled workers. Partial differentiation gives

$$
\frac{\partial \alpha}{\partial U}=\frac{-\beta(1-\beta)}{(\beta+(1-\beta) U)^{2}}<0 \quad \text { and } \quad \frac{\partial^{2} \alpha}{\partial U^{2}}=\frac{2 \beta(1-\beta)^{2}}{(\beta+(1-\beta) U)^{3}}>0
$$

and hence the fair wage constraint is negatively sloped and convex in $\frac{\omega}{q}-U$-space, i.e. higher rates of unemployment (for unskilled workers) lead firms to paying them relatively lower wages. This is because with higher rates of unemployment, the fair wage needed to elicit normal effort from unskilled workers is lower. Consider now the extreme cases $U=0$ and $U=1$ where we have

$$
\left.\frac{\omega}{q}\right|_{U=0}=1,\left.\quad \frac{\omega}{q}\right|_{U=1}=\beta
$$

Hence, wages can vary over the range $(\beta, 1)$, and the model gives us an intermediate case between full wage flexibility and a fixed wage differential. ${ }^{8}$ A graphical representation of the fair wage constraint is given in figure 1.

\section{General Equilibrium in the Closed Economy}

The general equilibrium in a closed economy is characterised by some degree of egalitarian attitudes among workers, i.e. $0<\beta<1$. The setup follows the model of Findlay and Kierzkowski (1983), to which we add the fair wage model of the labour market just described. It is assumed that at each point in time $N$ identical individuals are born that each live for $T>1$ periods. At birth they decide whether to remain unskilled and take up work immediately or to train for $\theta$

\footnotetext{
${ }^{8}$ With perfectly competitive markets for both types of labour, $\omega$ can vary between 0 and 1 .
} 


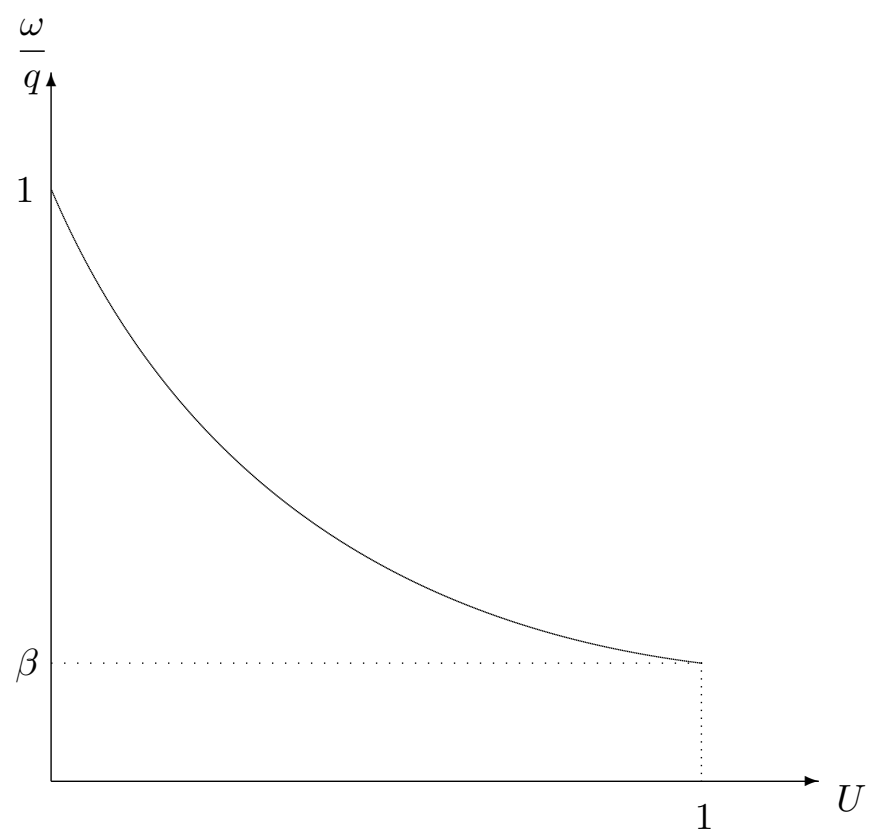

Figure 1: The Fair Wage Constraint

periods and then, being skilled now, work until they die. The length of education $\theta$ is assumed to be exogenous, and without further loss of generality it is normalised to one.

The economy is stationary, and at each point in time it is populated by $L=W T$ unskilled workers, a fraction $(1-U)$ of which is employed, $H=E(T-1)$ skilled workers, and $E$ students. $W=N-E$ denotes the number of people who at each instant take up work immediately after birth. Skill formation occurs according to the production function

$$
Q=F(K, E),
$$

where $K$ is the exogenous capital stock specific to the education sector. $F(\cdot)$ is assumed to be linearly homogenous in $(K, E)$ with partial derivatives $\partial Q / \partial E>0$ and $\partial^{2} Q / \partial E^{2}<0$. Consequently, we can write $q=f(k)$ with $k=K / E$ as the educational capital per student and 
$q=Q / E$ as the number of skill units per student.

Let $h$ denote the economy-wide skill intensity of production, measured in efficiency units. We then have

$$
h=\frac{Q(T-1)}{(N-E)(1-U) T} .
$$

The equilibrium skill intensity $h$ is determined by the condition that the present values of expected net lifetime incomes for skilled and unskilled labour are equal. Assuming that educational capital is paid its value marginal product, the net wage of skilled workers is equal to $\frac{\partial Q}{\partial E} w_{H}$. Using this, the career path indifference condition becomes

$$
\int_{1}^{T} \frac{\partial Q}{\partial E} w_{H} e^{-r t} d t=\int_{0}^{T} w_{L}(1-U) e^{-r t} d t
$$

where $r$ is the rate of interest, which equals the exogenous rate of time preference and is therefore constant in equilibrium. This condition can be rewritten as

$$
\frac{\partial Q}{\partial E}=\omega(1-U) \Delta
$$

with $\Delta \equiv\left(1-e^{-r T}\right) /\left(e^{-r}-e^{-r T}\right)>1$ as the ratio between expected net wage rates for skilled and unskilled workers in equilibrium. ${ }^{9} \Delta$ being larger than one reflects the two facts that skilled workers receive their net wage for a shorter period of time and later in their lifetime. Following the assumptions we have made earlier, $\Delta$ is a constant.

The economy is assumed to produce the two goods $X$ and $Y$, with skilled and unskilled labour as the only inputs. Good $Y$ serves as the numeraire and is assumed to be unskilled

\footnotetext{
${ }^{9}$ See Findlay and Kierzkowski (1983) for a step-by-step derivation of the analogous equation to (10) in the full employment variant of the model. All that distinguishes the present case from theirs is the replacement of $w_{L}$ by $w_{L}(1-U)$.
} 
labour intensive relative to $X$ at all common factor price ratios. Product markets are perfectly competitive, and production functions in both sectors exhibit constant returns to scale. Finally, preferences over goods are assumed to be homothetic with both $X$ and $Y$ being essential in consumption. With $p$ as the relative price of $X$ the zero profit conditions for the two sectors are given by the equality of goods prices to unit costs, i.e.

$$
c_{X}\left(w_{L}, w_{H}\right)=p \quad c_{Y}\left(w_{L}, w_{H}\right)=1 .
$$

Hence, as in the standard Heckscher-Ohlin model factor prices depend only on the relative goods price and we can write

$$
\omega=\psi(p) \quad \text { with } \quad \psi^{\prime}(p)<0
$$

where the sign of $\psi^{\prime}$ is implied by the Stolper-Samuelson theorem in combination with the factor intensity assumption. Furthermore, we have:

$$
p=\lambda(h) \quad \text { with } \quad \lambda^{\prime}(h)<0
$$

For any value of $h,(12)$ gives the equilibrium relative goods price. The sign of $\lambda^{\prime}$ follows from the assumptions of good $X$ being skill intensive and consumers having homothetic preferences. Under these assumptions, the Heckscher-Ohlin theorem ensures that the higher the skill-tolabour ratio of a country, the lower is its autarky price of the skill intensive good. Together, equations (7) to (12) determine the endogenous variables $p, \omega, U, E, Q$ and $h$.

Equilibrium for the closed fair wage economy can be illustrated in an $E-U$ diagram. $^{10}$ First, we combine (7), (8), (9), (11) and (12) to get

$$
Z \equiv \lambda^{-1}\left\{\psi^{-1}\left[\frac{Q \alpha(U, \beta)}{E}\right]\right\}-\frac{Q(T-1)}{(N-E)(1-U) T}=0 .
$$

\footnotetext{
${ }^{10}$ Davis and Reeve (2002) use a diagram of this type to describe equilibrium in the case of minimum wages.
} 
As shown in the appendix, implicit differentiation of (13) gives $d U / d E<0$. The intuition for this is as follows. An increase in E leads ceteris paribus to an increase in the number of skilled workers and consequently to an increase in the relative supply of the skill intensive good. The relative price of the skill intensive good will therefore fall, leading - via the Stolper-Samuelson link - to an increase in $\omega$. With perfectly flexible wages, this process would continue until $p$ has fallen sufficiently for consumers to be willing to consume the increased supply of the skill intensive good. The fair wage constraint prevents this from happening, and part of the adjustment occurs through a decrease in the rate of unemployment, i.e. an increase in the number of unskilled workers. Hence, goods and factor price changes are dampened in comparison to the standard full employment model.

A second relation between $E$ and $U$ can be derived by combining the fair wage constraint (7) with the condition for career path indifference, equation (10). To this end, we first divide both sides of (10) by $q$ to give

$$
\eta(E) \equiv \frac{\partial Q}{\partial E} \frac{E}{Q}=\frac{\omega}{q}(1-U) \Delta,
$$

where $\eta$ is the elasticity of educational output with respect to the number of students. With perfect competition in the education sector, $\eta$ is equal to the share of $E$ in educational output - i.e., the fraction of educational output that can be appropriated by the students. There is a straightforward interpretation for this representation of the career path indifference condition: ceteris paribus, whenever the gross wage differential becomes smaller ( $\omega / q$ increases), the share of educational output appropriated by the students has to increase in order to keep workers indifferent between being skilled and unskilled. Now, substituting the fair wage constraint into 
(10a) gives

$$
\eta(E) \equiv \frac{\partial Q}{\partial E} \frac{E}{Q}=\alpha(U, \beta)(1-U) \Delta
$$

and implicit differentiation yields

$$
\frac{d U}{d E}=\frac{\eta^{\prime}(E)}{\Delta\left[\frac{\partial \alpha}{\partial U}(1-U)-\alpha(U, \beta)\right]} \gtreqless 0 \quad \Longleftrightarrow \quad \eta^{\prime}(E) \lesseqgtr 0 .
$$

Hence the sign of the equilibrium relation between $E$ and $U$ along the career path indifference locus hinges crucially on how the students' share in educational output changes with the number of students. With a constant value of $\eta$ (i.e. the case where $F(\cdot)$ is a Cobb-Douglas production function), the rate of unemployment compatible with career path indifference does not change following a change in $E$. If $\eta$ increases with the number of students, the equilibrium relation between $E$ and $U$ along the career path indifference locus is negative, and vice versa. It is straightforward to show that with a linearly homogenous knowledge production function, as assumed, $\eta$ decreases in the number of students if and only if the elasticity of substitution $\varepsilon$ between $K$ and $E$ is smaller than one. ${ }^{11}$ Hence, the career path indifference locus (14) slopes upward in the inelastic case $(\varepsilon<1)$ and downward in the elastic case $(\varepsilon>1)$.

Figure 2 illustrates the determination of equilibrium for differing assumptions on the elasticity of substitution $\varepsilon$ (or, equivalently, differing assumptions on $\eta^{\prime}$ ). While the goods market equilibrium locus (13), denoted by GM, is downward sloping, the slope of the career path indifference locus (14) may have either sign: $\mathrm{CPI}_{1}$ shows the inelastic case $\left(\varepsilon<1, \eta^{\prime}<0\right)$, $\mathrm{CPI}_{2}$ describes the Cobb-Douglas case $\left(\varepsilon=1, \eta^{\prime}=0\right)$, and $\mathrm{CPI}_{3}$ applies in the elastic case $\left(\varepsilon>1, \eta^{\prime}>0\right)$.

\footnotetext{
${ }^{11}$ See Hicks (1963), ch. 6.
} 


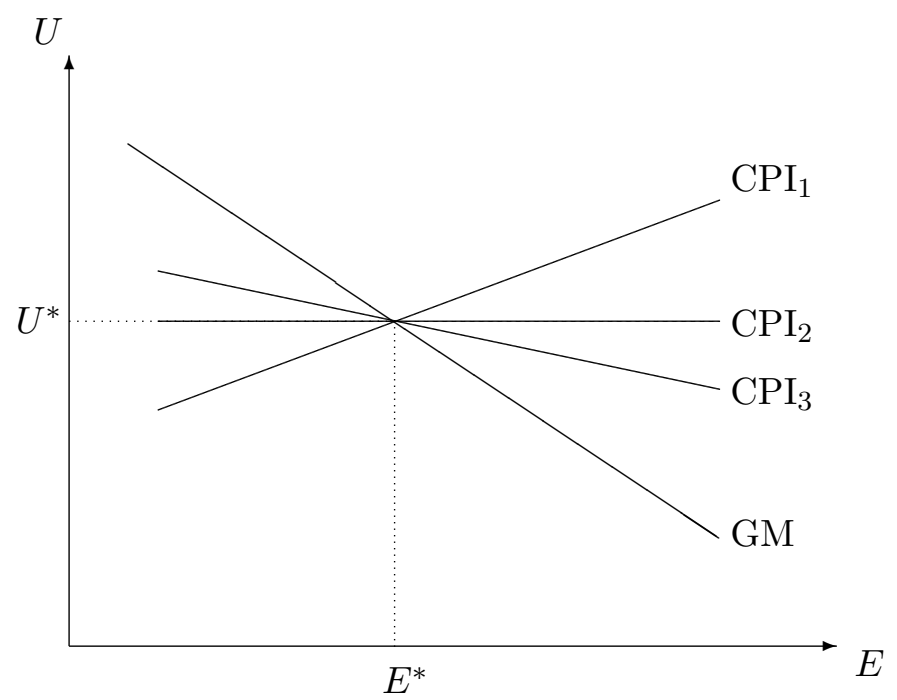

Figure 2: Equilibrium in the Fair Wage Economy

Consider now a globalisation shock hitting the previously closed fair wage economy. The shock is modelled as opening up to trade with the rest of world that at the relative autarky goods price of the fair wage economy is a net supplier of the unskilled labour intensive good. Formally, equation (12) is replaced by

$$
p=\lambda(h, G) \quad \text { with } \quad \frac{\partial \lambda}{\partial h}<0, \quad \frac{\partial \lambda}{\partial G}>0
$$

where $G$ represents the degree of globalisation vis-a-vis net suppliers of unskilled labour intensive goods that the fair wage economy faces. The modelling is very general in that it allows for the degree of globalisation to be determined by the rest of the world. For example, China becoming an exporter of unskilled labour intensive goods on a relevant scale would be one possible development captured by an increase in $G$. Ceteris paribus, this increases the relative price of the skill intensive good in the previously closed fair wage economy. 
From inspection of equations (13) and (14) one can see that $G$ influences the former but not the latter. Hence, changes in $G$ shift the GM locus in figure 2, but not the CPI locus. In the globalised fair wage economy, (13) is replaced by

$$
Z \equiv \lambda^{-1}\left\{\psi^{-1}\left[\frac{Q \alpha(U, \beta)}{E}\right], G\right\}-\frac{Q(T-1)}{(N-E)(1-U) T}=0
$$

and implicit differentiation shows that $d U / d G>0$ (see the appendix). In figure 2, an increase in $G$ therefore shifts the GM locus outwards (not drawn). Hence, we have the following:

Proposition 1. The globalisation shock increases the number of skilled workers in the fair wage economy. The unemployment rate of unskilled workers increases (decreases, remains constant) if the elasticity of substitution of the education production function is smaller than one (larger than one, equal to one).

It is straightforward to go on and derive the effects of globalisation on the other model variables. Given that the focus of the paper is on the effects globalisation has on an asymmetric two-country world, we refrain from doing so here.

\section{The Asymmetric Two-Country World}

\subsection{General Equilibrium}

Based on the description of the closed fair wage economy in the previous section, we can now derive equilibrium for an asymmetric two-country world of "Europe" and "America". The different preferences in America and Europe towards wage inequality are captured here by assuming that $0<\beta^{A}<\beta^{E}<1$, where $\beta^{A}$ and $\beta^{E}$ apply to America and Europe, respectively. 
That is to say, European workers have a stronger preference for wage compression than their American colleagues. ${ }^{12}$ Assuming that the two countries share the same technology in both $X$ and $Y$ production, and that they both produce both goods and trade them freely with each other, factor prices for efficiency units of skilled and unskilled labour will be equalised internationally. In order to focus on the effect of differing attitudes, we assume America and Europe to be identical in all other respects, including endowments with $K$ and $N$. Then, the two-country equilibrium is formally described by

$$
\begin{array}{rlrl}
\frac{\omega}{q^{i}} & =\frac{\beta^{i}}{\beta^{i}+\left(1-\beta^{i}\right) U^{i}} & & i=E, A \\
Q^{i} & =F\left(K^{i}, E^{i}\right) & & i=E, A \\
h & =\frac{\left(Q^{A}+Q^{E}\right)(T-1)}{\left[\left(N^{A}-E^{A}\right)\left(1-U^{A}\right)+\left(N^{E}-E^{E}\right)\left(1-U^{E}\right)\right] T} & \\
\frac{\partial Q^{i}}{\partial E^{i}} & =\omega\left(1-U^{i}\right) \Delta & i=E, A
\end{array}
$$

as well as (11) and (16). In general, the superscript $E$ denotes variables specific to Europe, and superscript $A$ those specific to America. Equations $\left(7^{\prime}\right)$ are the fair wage constraint for Europe and America, respectively. Equations $\left(8^{\prime}\right)$ describe the knowledge production in Europe and America, respectively, the production function being the same for both countries. The average skill intensity of world production is given by $\left(9^{\prime}\right)$, and $\left(10^{\prime}\right)$ are the conditions for equality of expected lifetime incomes for skilled and unskilled workers in Europe and America. Together, these nine equations determine the endogenous variables $p, \omega, h, E^{E}, E^{A}, Q^{E}, Q^{A}, U^{E}$ and $U^{A}$.

\footnotetext{
${ }^{12}$ This is a milder version of the dichotomy assumed in the small open economy model of Agell and Lundborg (1995b). They assume - using a fair wage mechanism different from the one employed here - that relative factor prices have an influence on the effort provided by workers in "Europana", while workers in "Americana" do not care about relative factor prices.
} 


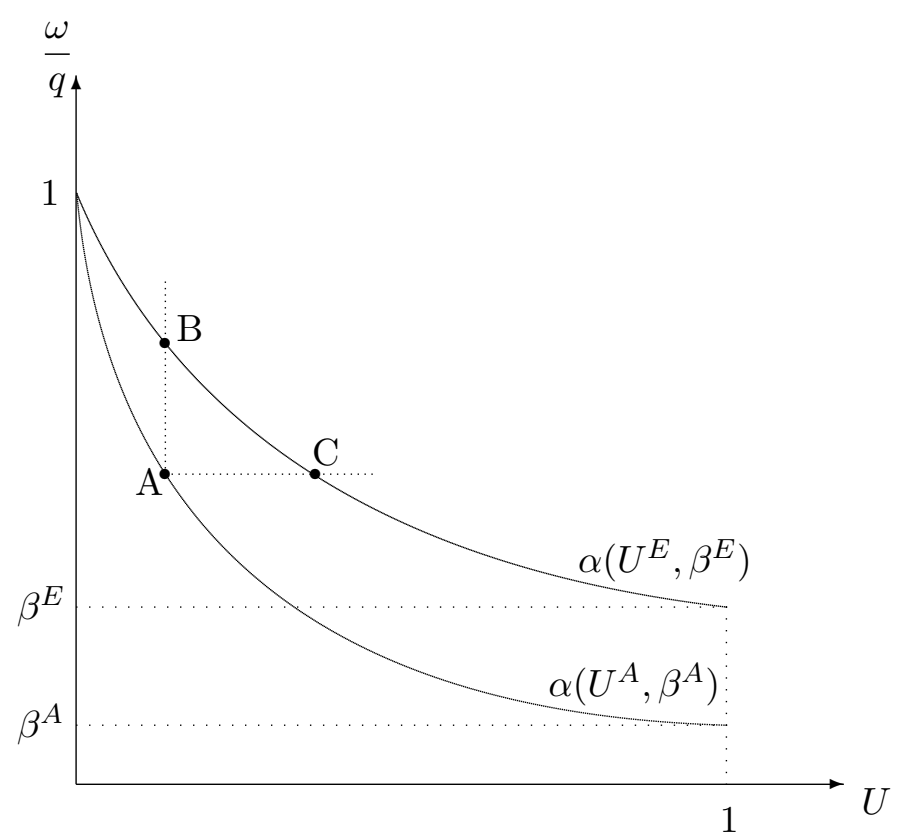

Figure 3: European and American Fair Wage Constraints

It is now straightforward to show the following:

Proposition 2. In equilibrium, the unemployment rate among unskilled workers is higher in Europe than in America, and the skill premium in terms of both gross and net wages is lower.

Proof. The first part of the proof is by contradiction. Assume $U^{A} \geq U^{E}$. This implies $E^{A} \geq E^{E}$, $q^{A} \leq q^{E}$, and $\omega / q^{A} \geq \omega / q^{E}$ (from $\left(10^{\prime}\right)$ ). However, $U^{A} \geq U^{E} \Rightarrow \omega / q^{A}<\omega / q^{E}$ from $\left(7^{\prime}\right)$ and the assumption $\beta^{E}>\beta^{A}$, which is a contradiction to the above. Hence, we have $U^{E}>U^{A}$. Now, $U^{E}>U^{A} \Rightarrow \omega / q^{E}>\omega / q^{A}$ (from $\left(10^{\prime}\right)$ ), which is consistent with $\left(7^{\prime}\right)$ and the assumption $\beta^{E}>\beta^{A}$. In addition, $U^{E}>U^{A} \Rightarrow \omega / \frac{\partial Q^{E}}{\partial E^{E}}>\omega / \frac{\partial Q^{A}}{\partial E^{A}}\left(\right.$ from $\left.\left(10^{\prime}\right)\right)$.

The two fair wage constraints are depicted in figure 3. From (7), we have $\partial \alpha / \partial \beta>0$ for $U>0$, 
and hence the European fair wage constraint lies strictly above the American one for positive unemployment levels. Let $\mathrm{A}$ in figure 3 be the equilibrium combination of $U$ and $\omega / q$ in America. Then, proposition 2 says that equilibrium in Europe will lie somewhere between points B and C. ${ }^{13}$

Corollary 1. Gross and net wages of skilled workers are higher in America than in Europe.

Proof. Wages for unskilled workers are equalised through trade. This, together with proposition 2 immediately gives the result.

The economic intuition is straightforward: Ceteris paribus, the higher unemployment rate for unskilled workers in Europe gives them an additional incentive to become skilled, thereby reducing the average quality of skilled workers and hence the wage they receive.

Using proposition 2, we can derive the trade pattern for the two-country world. Let $h^{i}$ denote the average skill intensity of production in country $i$. We then have

$$
h^{E}-h^{A}=\frac{T-1}{T}\left[\frac{Q^{E}}{\left(\frac{N}{2}-E^{E}\right)\left(1-U^{E}\right)}-\frac{Q^{A}}{\left(\frac{N}{2}-E^{A}\right)\left(1-U^{A}\right)}\right]>0
$$

because $U^{E}>U^{A} \Rightarrow E^{E}>E^{A} \Rightarrow Q^{E}>Q^{A}$. Hence, the average skill intensity of production in Europe is higher than the average skill intensity of production in America. With identical homothetic preferences and costless goods trade, the skill intensity of consumption is equalised across countries. Europe therefore exports the skill intensive good and imports the unskilled labour intensive good.

\footnotetext{
${ }^{13}$ Note that proposition 2 does not depend on the elasticity of substitution in the education sector.
} 


\subsection{Comparative Statics}

The effects of a globalisation shock on the asymmetric two-country world can be analyzed by using a figure analogous to figure 2 . In particular, we derive the goods market equilibrium locus and the career path indifference locus for Europe in $U^{E}-E^{E}$-space, taking into account the interaction between the two countries' factor markets working through integrated goods markets. The GM-locus is now described by

$$
Z \equiv \lambda^{-1}\left\{\psi^{-1}(\omega), G\right\}-\frac{\left(Q^{A}+Q^{E}\right)(T-1)}{\left[\left(N^{A}-E^{A}\right)\left(1-U^{A}\right)+\left(N^{E}-E^{E}\right)\left(1-U^{E}\right)\right] T}=0
$$

where $\omega=\omega\left(\frac{Q^{E} \alpha\left(U^{E}\right), \beta^{E}}{E^{E}}\right)$. It is shown in the appendix that the GM-locus is downward sloping in $U^{E}-E^{E}$-space. ${ }^{14}$ The economic logic is analogous to the logic for the closed economy described in section 4 above.

The CPI locus for Europe is given by

$$
\eta\left(E^{E}\right)=\alpha\left(U^{E}, \beta^{E}\right)\left(1-U^{E}\right) \Delta,
$$

which is identical to (14) but for the fact that $E^{E}, U^{E}$ and $\beta^{E}$ have been substituted for $E$, $U$ and $\beta$. Consequently, the condition on the slope of the CPI-locus is completely analogous to the condition for the one-country world: It is upward sloping in $U^{E}-E^{E}$ space if and only if the substitution elasticity of the education production function is smaller than one, implying $\eta^{\prime}<0$. The equilibrium values of $U^{E}$ and $E^{E}$ can now be derived graphically. Figure 4 focuses on the inelastic case $\left(\mathrm{CPI}_{1}\right)$ and the Cobb-Douglas case $\left(\mathrm{CPI}_{2}\right)$, respectively, as the elastic case does not appear to be relevant from an empirical point of view. $E_{0}^{E}$ and $U_{0}^{E}$ then describe the equilibrium values in the closed two-country world.

\footnotetext{
${ }^{14}$ As $\omega$ changes endogenously along the GM-locus, so do $E^{A}, U^{A}$ and $Q^{A}$.
} 


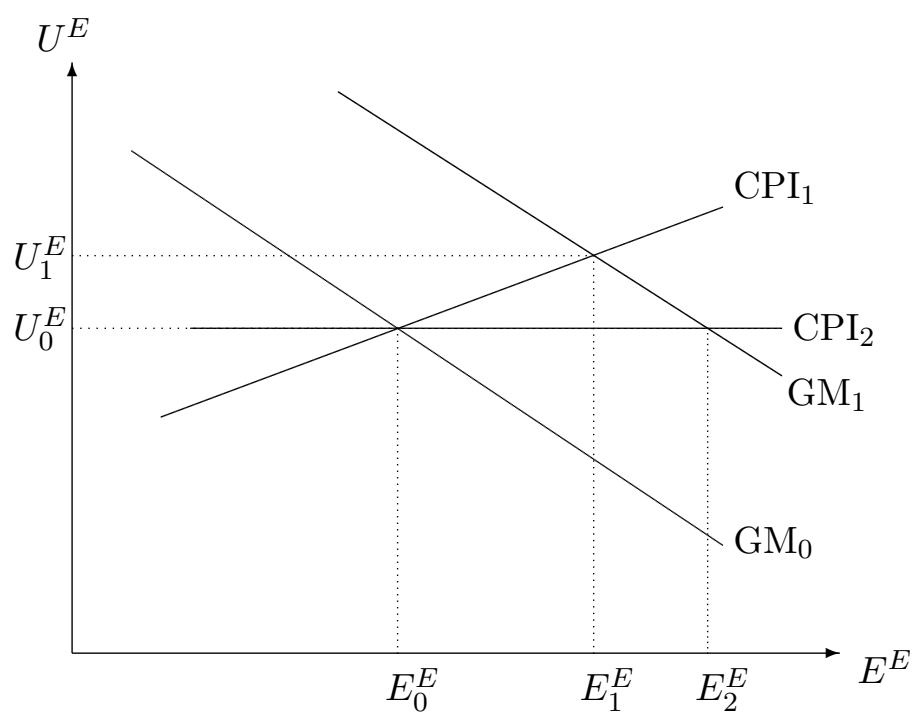

Figure 4: Globalisation Shock to the Two-Country World

Now, we analyze the effect of a globalisation shock on the asymmetric two-country world. As explained above, the idea is that of a previously closed newly industrializing country, "China", to enter trade with America and Europe. All that is assumed is that at the pre-globalisation relative goods price, China is a net supplier of the unskilled labour intensive good. ${ }^{15}$ In terms of figure 4, one can show (see the appendix) that the globalisation shock shifts the GM-locus outwards. That is, for a given number of students in Europe an increase in the European unemployment rate is required in order to restore goods market equilibrium, allowing for the induced adjustment in the American labour market. The new equilibrium values are $\left(U_{0}^{E}, E_{2}^{E}\right)$ in the Cobb-Douglas case and $\left(U_{1}^{E}, E_{1}^{E}\right)$ in the inelastic case. Hence, the globalisation shock increases the number of skilled workers in Europe in both cases considered. Clearly, an analogous

\footnotetext{
${ }^{15}$ No assumptions on China's production technology or factor endowments are made.
} 
analysis would yield a qualitatively identical result for America. Using this result, we are now in a position to give a comprehensive description of equilibrium changes brought about by the globalisation shock in American and European labour markets. The Cobb-Douglas case gives a set of useful reference results:

Proposition 3. With a Cobb-Douglas production function in the education sector, the globalisation shock leaves the rate of unemployment among unskilled workers as well as the gross and net wage differentials constant in both America and Europe.

Proof. Start by dividing both sides of $\left(10^{\prime}\right)$ by $q^{i}$ for $i=A, E$. In the Cobb-Douglas case, the LHS of the resulting equations is constant, and hence so are $U^{i}$ and $\omega / q^{i}$. From $\left(10^{\prime}\right)$, with $\Delta$ and $U^{i}$ constant, so have to be the net wage differentials $\omega / \frac{\partial Q^{i}}{\partial E^{i}}$.

Intuitively, the globalisation shock as a negative shock to the demand for unskilled workers gives an incentive for unskilled workers in both countries to become skilled. With a CobbDouglas production function in education, these supply side responses are such that the unemployment rates are kept on their respective old equilibrium levels. Given the fair wage constraint, profit maximizing firms then choose to hold the gross wage differential constant. The increase of the wage differential in efficiency units is exactly offset by a decrease in the average quality of the skilled workers, i.e., the number of skill units per skilled worker.

Given that the data on changes in wage inequality, as presented for instance in Acemoglu (2003), show an increase in gross wage differentials in America and - at least in some cases - in Europe as well, the results of the Cobb-Douglas benchmark case are at odds with the empirical evidence. We now turn to the inelastic case. This yields the following results: 
Proposition 4. With the elasticity of substitution in the education sector smaller than one, the globalisation shock

(i) increases the rate of unemployment among unskilled workers as well as gross wage differentials in both America and Europe,

(ii) decreases skill premia in terms of net wages in America and Europe.

Proof. Again, start by dividing both sides of $\left(10^{\prime}\right)$ by $q^{i}$ for $i=A, E$. With $\varepsilon<1$, an increase in $E^{i}$ now leads to a decrease in the LHS of the resulting equations, and hence to an increase in $U^{i}$ as well as a decrease in $\omega / q^{i}$ (i.e. an increase in the gross wage differential). From $\left(10^{\prime}\right)$, an increase in $U^{i}$ implies an increase in $\omega / \frac{\partial Q^{i}}{\partial E^{i}}$ (i.e. a decrease in the net wage differential).

Intuitively, with an elasticity of substitution smaller than in the Cobb-Douglas reference case, the supply side reaction induced by the negative demand shock to unskilled labour is not as strong, and hence the economy settles down at a higher rate of unemployment among unskilled workers. Via the fair wage constraint, this implies a higher skill premium in terms of gross wages. The career path indifference condition requires that the increase in the rate of unemployment for the unskilled (which makes skill acquisition more attractive) is accompanied in the new equilibrium by a decrease in the skill premium in terms of net wages (which makes skill acquisition less attractive). Without further restrictions on the production function in the education sector, it is unclear whether the unemployment or wage differentials between Europe and America widen or shrink. It is clear from proposition 2 however, that the globalisation shock leaves the ranking of Europe and America in terms of wage differentials and unemployment rates unchanged. Therefore, while the "straightjacket" of factor price equalisation is loosened in the 
present model, international goods market integration still imposes constraints the international divergence of factor prices.

\section{Conclusion}

In the one-cone HO model, modified to allow for labour market asymmetries between countries, a globalisation shock cannot be reconciled with internationally divergent wage paths. Due to the basic factor price equalisation property of the model, country-specific technology shocks are the only possible source of changes in international factor price differentials. Empirical evidence cited above supports the idea that fair wage considerations are important to firms' wage setting in both America and Europe. Building on this evidence, the present paper shows that a globalisation shock can have differential effects on both unemployment and wage rates in America and Europe if an asymmetric two-country version of the fair wage model by Akerlof and Yellen (1990) is merged with the Findlay-Kierzkowski model, which allows for endogenous changes of factor supplies in a HO framework. It is shown that the production technology in the education sector plays a crucial role for the adjustment process, because it determines the extent to which an induced supply side adjustment in the labour market compensates the demand side shock. Consequently, a further source for differential adjustment to the globalisation shock, not explored here, would be international differences in education technology.

Analysing social welfare - rather than distributional - issues in the present framework would require to be more specific on the job allocation mechanism for unskilled workers. In particular, it is relevant whether employed and unemployed workers have different consumption levels. For the case where they do, Davidson, Martin and Matusz (1994) show that in a wide variety of 
overlapping generations models with involuntary unemployment Samuelsonian surpluses exist and the allocation that maximizes the steady-state value of output is not Pareto-optimal. Given the overlapping-generations structure of the model in this paper, we can expect this result to be relevant here as well. An investigation along those lines appears to be promising but is left for future research.

\section{Appendix}

\section{The GM-locus in the Closed Fair Wage Economy}

In order to facilitate notation, we introduce $q=g(E, K)$ with $\partial g / \partial E<0$. Then, implicitly differentiating (13) gives

$$
\frac{d U}{d E}=-\frac{\frac{\partial Z}{\partial E}}{\frac{\partial Z}{\partial U}}=-\frac{\left(\lambda^{-1}\right)^{\prime}\left(\psi^{-1}\right)^{\prime} \frac{\partial g}{\partial E} \alpha-\frac{N(T-1)}{(N-E)^{2}(1-U) T}}{\left(\lambda^{-1}\right)^{\prime}\left(\psi^{-1}\right)^{\prime} g \frac{\partial \alpha}{\partial U}-\frac{E(T-1)}{(N-E)(1-U)^{2} T}}<0,
$$

and hence the GM-locus is downward sloping in $U-E$-space in the closed fair wage economy.

By implicit differentiation of (17) we get

$$
\frac{d U}{d G}=-\frac{\frac{\partial Z}{\partial G}}{\frac{\partial Z}{\partial U}}=-\frac{\frac{\partial\left(\lambda^{-1}\right)}{\partial G}}{\frac{\partial\left(\lambda^{-1}\right)}{\partial p}\left(\psi^{-1}\right)^{\prime} g \frac{\partial \alpha}{\partial U}-\frac{E(T-1)}{(N-E)(1-U)^{2} T}}>0
$$

and hence opening up the closed fair wage economy to globalisation shifts the GM-locus upwards in $U-E$-space.

\section{The GM-locus in the Two-Country World}

In analogy to the previous section, we use $q^{i}=g\left(E^{i}, K^{i}\right), i=A, E$, with $\partial g / \partial E^{i}<0$. Furthermore, it follows from $\left(10^{\prime}\right)$ that we can define a function

$$
E^{A}=R\left(\omega, U^{A}, K^{A}\right)
$$


where

$$
U^{A}=\alpha^{-1}\left(\frac{\omega}{g\left(E^{A}, K^{A}\right)}, \beta^{A}\right)
$$

We then have

$$
X \equiv E^{A}-R\left(\omega, \alpha^{-1}\left(\frac{\omega}{g\left(E^{A}, K^{A}\right)}, \beta^{A}\right), K^{A}\right)
$$

and implicit differentiation gives

$$
\frac{d E^{A}}{d \omega}=-\frac{\partial X / \partial \omega}{\partial X / \partial E^{A}}=\frac{\frac{\partial R}{\partial \omega}+\frac{\partial R}{\partial U^{A}} \frac{\partial\left(\alpha^{-1}\right)}{\partial\left(\omega / q^{A}\right)} \frac{1}{q^{A}}}{1+\frac{\partial R}{\partial U^{A}} \frac{\partial\left(\alpha^{-1}\right)}{\partial\left(\omega / q^{A}\right)}\left(\frac{\omega}{\left(q^{A}\right)^{2}}\right) \frac{\partial g}{\partial E^{A}}}<0 .
$$

The fair wage constraint can be rewritten as $\omega=\alpha\left(U^{E}, \beta^{E}\right) g\left(E^{E}, K^{E}\right)$. Then, implicitly differentiating (19) gives

$$
\begin{aligned}
& \frac{d U^{E}}{d E^{E}}=-\frac{\frac{\partial Z}{\partial E^{E}}}{\frac{\partial Z}{\partial U^{E}}} \\
& =-\left\{\frac{\partial\left(\lambda^{-1}\right)}{\partial p}\left(\psi^{-1}\right)^{\prime} \frac{\partial g}{\partial E^{E}} \alpha\right. \\
& -\frac{1}{\mathcal{D}^{2}}\left[\left(\frac{\partial Q^{A}}{\partial E^{A}} \frac{d E^{A}}{d \omega} \frac{\partial g}{\partial E^{E}} \alpha+\frac{\partial Q^{E}}{\partial E^{E}}\right)(T-1) \mathcal{D}\right. \\
& \left.\left.+\left(\frac{d E^{A}}{d \omega} \frac{\partial g}{\partial E^{E}} \alpha\left(1-U^{A}\right)+\left(N^{A}-E^{A}\right) \frac{\partial U^{A}}{\partial \omega} \frac{\partial g}{\partial E^{E}} \alpha+1-U^{E}\right) T \mathcal{N}\right]\right\} \\
& \times\left\{\frac{\partial\left(\lambda^{-1}\right)}{\partial p}\left(\psi^{-1}\right)^{\prime} g \frac{\partial \alpha}{\partial U^{E}}\right. \\
& \left.-\frac{\frac{\partial Q^{A}}{\partial E^{A}} \frac{d E^{A}}{d \omega} g \frac{\partial \alpha}{\partial U^{E}}(T-1) \mathcal{D}+\left(\frac{d E^{A}}{d \omega} g \frac{\partial \alpha}{\partial U^{E}}\left(1-U^{A}\right)+N^{E}-E^{E}\right) T \mathcal{N}}{\mathcal{D}^{2}}\right\}^{-1}<0
\end{aligned}
$$

where

$$
\mathcal{N} \equiv\left(Q^{A}+Q^{E}\right)(T-1), \quad \mathcal{D} \equiv\left[\left(N^{A}-E^{A}\right)\left(1-U^{A}\right)+\left(N^{E}-E^{E}\right)\left(1-U^{E}\right)\right] T .
$$


Hence the GM-locus is downward sloping in $U^{E}-E^{E}$-space in the asymmetric two-country world. By implicit differentiation of (19) we get

$$
\begin{aligned}
\frac{d U^{E}}{d G}= & -\frac{\frac{\partial Z}{\partial G}}{\frac{\partial Z}{\partial U^{E}}}= \\
& -\frac{\partial\left(\lambda^{-1}\right)}{\partial G} \times\left\{\frac{\partial\left(\lambda^{-1}\right)}{\partial p}\left(\psi^{-1}\right)^{\prime} g \frac{\partial \alpha}{\partial U^{E}}\right. \\
& \left.-\frac{\frac{\partial Q^{A}}{\partial E^{A}} \frac{d E^{A}}{d \omega} g \frac{\partial \alpha}{\partial U^{E}}(T-1) \mathcal{D}+\left(\frac{d E^{A}}{d \omega} g \frac{\partial \alpha}{\partial U^{E}}\left(1-U^{A}\right)+N^{E}-E^{E}\right) T \mathcal{N}}{\mathcal{D}^{2}}\right\}^{-1}>0
\end{aligned}
$$

and hence opening up the two-country world to globalisation shifts the GM-locus upwards in $U^{E}-E^{E}$-space. 


\section{References}

ACEMOGLU, D. (2003), "Cross-Country Inequality Trends", Economic Journal, 113, F121F149.

AGELL, J. and LUNDBORG, P. (1995a), "Theories of Pay and Unemployment: Survey Evidence from Swedish Manufacturing Firms", Scandinavian Journal of Economics, 97, 295307.

AGELL, J. and LUNDBORG, P. (1995b), "Fair Wages in an Open Economy", Economica, 62, $335-351$.

AGELL, J. and LUNDBORG, P. (2003), "Survey Evidence on Wage Rigidity and Unemployment: Sweden in the 1990s", Scandinavian Journal of Economics, 105, 15-29.

AKERLOF, G. (1982), "Labor Contracts as Partial Gift Exchange", Quarterly Journal of Economics, 97, 543-569.

AKERLOF, G. and YELLEN, J. (1990), "The Fair Wage-Effort Hypothesis and Unemployment", Quarterly Journal of Economics, 105, 255-283.

BEWLEY, T. (1999) Why Wages don't Fall During a Recession (Cambridge, MA: Harvard University Press).

DAVIDSON, C., MARTIN, L. and MATUSZ, S. (1994), "Jobs and Chocolate: Samuelsonian Surpluses in Dynamic Models of Unemployment", Review of Economic Studies, 61, 173192. 
DAVIS, D. (1998), "Does European Unemployment Prop up American Wages? National Labor Markets and Global Trade", American Economic Review, 88, 478-494.

DAVIS, D. and REEVE, T. (2002), "Human Capital, Unemployment and Relative Wages in a Global Economy", in D. Greenaway et al. (eds.) Trade, Investment, Migration and Labour Market Adjustment (Basingstoke:Palgrave Macmillan) 7-27.

FEHR, E. and FALK, A. (1999), "Wage Rigidity in a Competitive Incomplete Contract Market", Journal of Political Economy, 107, 106-134.

FINDLAY, R. and KIERZKOWSKI, H. (1983), "International Trade and Human Capital: A Simple General Equilibrium Model”, Journal of Political Economy, 91, 957-978.

HICKS, J. (1963) The Theory of Wages, 2nd ed. (London: Macmillan).

KRUGMAN, P. (1995), "Growing World Trade: Causes and Consequences", Brookings Papers on Economic Activity, n.V., 327-362.

KRUGman, P. (2000), "Technology, Trade and Factor Prices", Journal of International Economics, 50, 51-71.

SOLOW, R. (1979), "Another Possible Source of Wage Stickiness", Journal of Macroeconomics, $1,79-82$. 